\title{
Impact of the Type and Number of Composite Layers in Flexural Strengthening of Reinforced Concrete Voided Slabs with FRP Using Finite Element Method
}

\author{
Muhammed MALEKNIA $^{1}$, Ataollah hajati MODARAEI ${ }^{2}$ \\ 1. Structural Engineering MS, Guilan University, Mohamad_maleknia@yahoo.com \\ 2. Assistant Professor, Guilan University, Modaraei@kadous.gu.ac.ir
}

\begin{abstract}
The increasing use of FRP composites to strengthen and repair the structural bearing components, also low weight, high flexibility, ease of transportation, high speed, ease of cutting in desired sizes, ease of performance and possibility of external strengthening are the major reasons for using the FRP laminates in repairing concrete structures compared to other methods. One usage of FRP laminates is strengthening the reinforced concrete slabs. Present article studied the impact of type and number of composite layers in flexural strengthening of the reinforced concrete voided slabs with FRP laminates. The voided slabs are used to reduce concreting volume, costs and also decreasing weight of the structure. Some of these buildings and bridges have been severely damaged due to natural disasters including earthquake, wind or fatigue of materials and alkaline and acidic corrosive agents. Therefore, repair and strengthening the bearing surfaces of above structures is vital and economical. Present research has investigated the parametric study of the impact of type and thickness of FRP fibers on flexural behaviour of strengthened voided slabs using different FRP systems (CFRP-GFRP). For this purpose, the voided concrete ceiling is modelled in ANSYS software, then it is compared to the available laboratory model for verification of the problem. After the verification, by changing the parameters of type and thickness of RFP fibers in the modelled voided slab, ultimate strength of the slab has been studied. These studies have showed that the slabs retrofitted with GFRP fibers have a better ductility compared to the slabs retrofitted with CFRP fibers, but ultimate strength of the slabs retrofitted with CFRP is significantly more than the slabs strengthened with GFRP fibers. It was also found that by increase in the number of laminated composite layers in retrofitted voided slabs, ultimate capacity of the voided slabs is increased.
\end{abstract}

Keywords: Voided Slab, Flexural Strengthening, Laminated Composite, Thickness of Fibers, CFRP and GFRP Fibers.

\section{Introduction}

Lots of the reinforced concrete structures in the world have been experiencing substantial damages due to contact with sulfates, chlorides and other corrosive agents. This has caused lots of costs for repairing, reconstruction or substituting the damaged structures all around the world and its consequences have sometimes been considered as not only an engineering problem, but as a serious social problem [1]. Due to the increasing need to use combined 
materials to obtain desired properties and functions, use of the composite materials has been considerably increased in construction industry and it is developing with a high speed. The first researches done in this field began in early 1980's. But the earthquakes of California 1990 and Kobe 1995 were important and effective factors for a comprehensive review of applying polymer composites made of FRP fibers for strengthening and retrofitting the concrete and building constructions in earthquake-prone areas [2].

Despite the extensive researches in field of reinforced concrete beams and pillars, little researches have been done on concrete slabs especially the voided slabs. Present research studies the impact of the type and number of FRP layers in the voided slab on the ultimate strength obtained from the retrofitting, using one of the effective and new methods, the flexural strengthening using the FRP laminated composites. A very strong software in field of engineering and strengthening the structures is the ANSYS ${ }^{*}$ software. This software is one of the analytic software which uses the finite element method for modeling and analysis [3]. Sections of interest in this article have been modeled and studied using ANSYS software.

\section{Modeling}

Present research studies the impact of type and number of composite layers (thickness of FBR plates) on flexural behavior of the reinforced concrete voided slabs strengthened with FRP laminates. At the beginning, to determine the accuracy of behaviour of the models and the results presented in this article, a sample beam called the control sample is modelled in ANSYS software that its geometrical and physical properties are explained in the following. Then, the loading-deformation diagram of middle of the beam, the load which has caused the primary cracks of the slab, the ultimate load and the crack pattern in the final moment are studied. Ultimately, the results are compared to the laboratory sample of the research work by "Mohammad Mehdi Salehi Yanesari and Ali Modanlou" titled the Flexural and FlexuralShearing strengthening of the reinforced concrete voided slabs using CFRP and GFRP fibers and steel laminates [4]. This research [4] has studied the flexural behaviour of the voided reinforced concrete slabs strengthened using different types of FRP and steel lamintes and laboratory samples. For this purpose, 8 voided reinforced concrete slab samples with a size of $150 \times 45 \times 20 \mathrm{~cm}$ were made with a tensile reinforcement ratio of $\left(\rho_{b}=0.25 \rho_{\max }\right)$ according to Aba regulations. 6 number 12 rebars have been used as tensile reinforcement and four number 8 rebars have been used as pressure rebar. Shear reinforcements with a diameter of 6 $\mathrm{mm}$ are placed in center to center $10 \mathrm{~cm}$ (side one-third) and $20 \mathrm{~cm}$ (in the middle threefifth) distances of the slabs from each other. Also, number 6 rebars have been used in $15 \mathrm{~cm}$ center to center distances as the thermal rebars above and below the slabs in a direction perpendicular to the main rebars. Two openings showing the voided slabs with a diameter of $10 \mathrm{~cm}$ has been created in whole length of the slab.

Properties and rebar tying manner of the slabs have been shown in figure 1. 

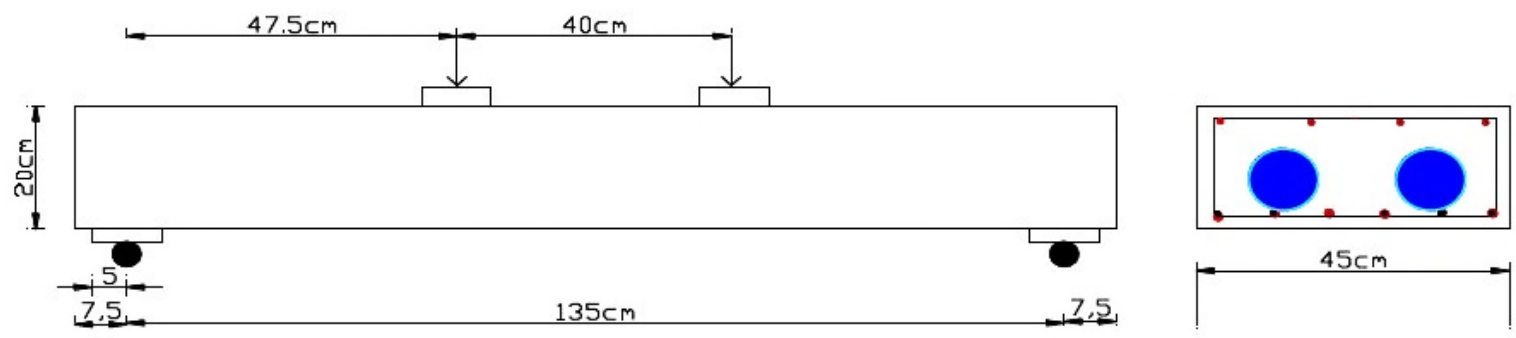

Fig. 1: Slabs specifications [4]

\section{Strengthening and Applied Elements Pattern}

In ANSYS program, Solid65 element has been used for modeling the concrete, Link180 for modeling the reinforcement, SHELL43 surface element for modelling FRP and Solid45 for modelling the metal plates under the backrest and under the concentrated load (to reduce the impact of stress concentration).

\section{Physical Properties}

Physical properties of FRP fibres are as table 1 shows.

Table 1: Fibers specifications

\begin{tabular}{|c|c|c|c|c|c|}
\hline \multirow{2}{*}{ FRP } & $\begin{array}{c}\text { Modulus of } \\
\text { elasticity } \\
\text { composite }\end{array}$ & $\begin{array}{c}\text { Poisson's } \\
\text { ratio }\end{array}$ & $\begin{array}{c}\text { Tensile } \\
\text { strength } \\
\text { Mpa } \\
(\mathrm{ksi})\end{array}$ & $\begin{array}{c}\text { Shear } \\
\text { modulus } \\
\text { Mpa } \\
(\mathrm{ksi})\end{array}$ & $\begin{array}{c}\text { Any layer } \\
\text { thickness } \\
\text { mm } \\
(\mathrm{in})\end{array}$ \\
\hline \multirow{5}{*}{ CFRP } & $\mathrm{E}_{\mathrm{x}}=62,000(9000)$ & $\mathrm{V}_{\mathrm{xy}}=0.22$ & & & \\
& $\mathrm{E}_{\mathrm{y}}=4800(700)$ & $\mathrm{V}_{\mathrm{xz}}=0.22$ & 958 & $\mathrm{G}_{\mathrm{xy}}=3270(474)$ & $\mathrm{G}_{\mathrm{xz}}=3270(474)$ \\
& $\mathrm{E}_{\mathrm{z}}=4800(700)$ & $\mathrm{V}_{\mathrm{yz}}=0.3$ & $(138)$ & $\mathrm{G}_{\mathrm{yz}}=1860(270)$ & $(0.040)$ \\
\hline \multirow{5}{*}{ GFRP } & $\mathrm{E}_{\mathrm{x}}=21,000(3000)$ & $\mathrm{V}_{\mathrm{xy}}=0.26$ & & & \\
& $\mathrm{E}_{\mathrm{y}}=7000(1000)$ & $\mathrm{V}_{\mathrm{xz}}=0.26$ & 600 & $\mathrm{G}_{\mathrm{xy}}=1520(220)$ & $\mathrm{G}_{\mathrm{xy}}=1520(220)$ \\
& $\mathrm{E}_{\mathrm{z}}=7000(1000)$ & $\mathrm{V}_{\mathrm{yz}}=0.3$ & $(87)$ & $\mathrm{G}_{\mathrm{xy}}=2650(385)$ & $(0.050)$ \\
\hline
\end{tabular}

Specifications of the concrete for the control voided slab have been shown in table 2 .

Table 2: Specifications of control concrete voided slab

\begin{tabular}{|c|c|c|}
\hline fc(Mpa) & Ecu(Mpa) & \multirow{2}{*}{ Control slab } \\
\cline { 1 - 2 } 25 & 25000 & \\
\hline
\end{tabular}


Properties of Steel:

It is assumed that steel is a perfect ideal elastoplastic material.

$\mathrm{E}_{\mathrm{s}}=200000 \mathrm{Mpa} \quad$ Modulus of elasticity

$\mathrm{f}_{\mathrm{y}}=400 \mathrm{Mpa} \quad$ Steel flow stress

$\mathrm{v}=0.3 \quad$ Poisson's ratio

\section{Beam Geometry and Rebar Binding Manner}

To study the behaviour of the voided slab, a slab with a size of $150 \times 45 \times 20 \mathrm{~cm}$ has been created and two holes with a diameter of $10 \mathrm{~cm}$ are considered in the middle and along the length of the slab which are observed in figures 2 and 3.
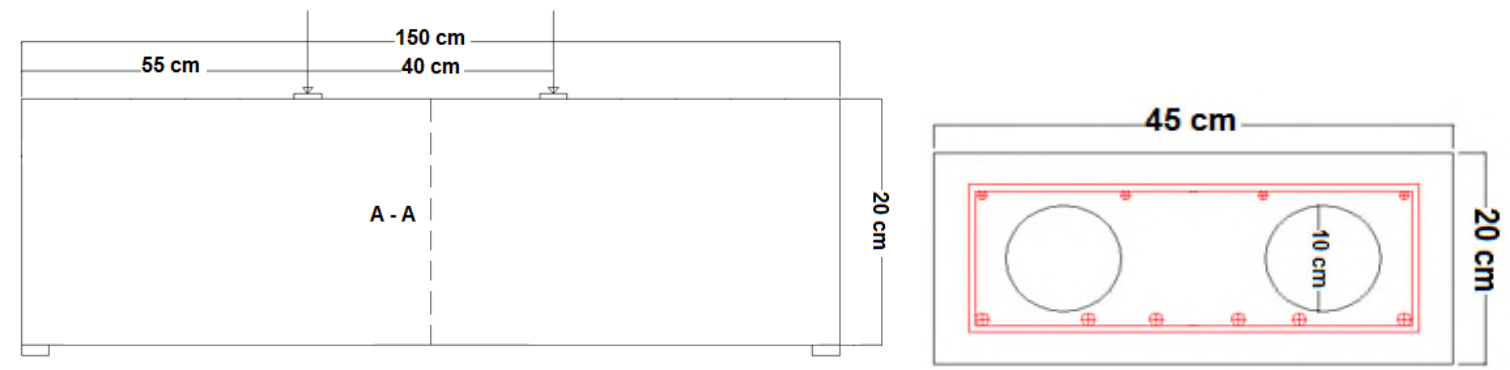

Fig. 2: Slabs specifications

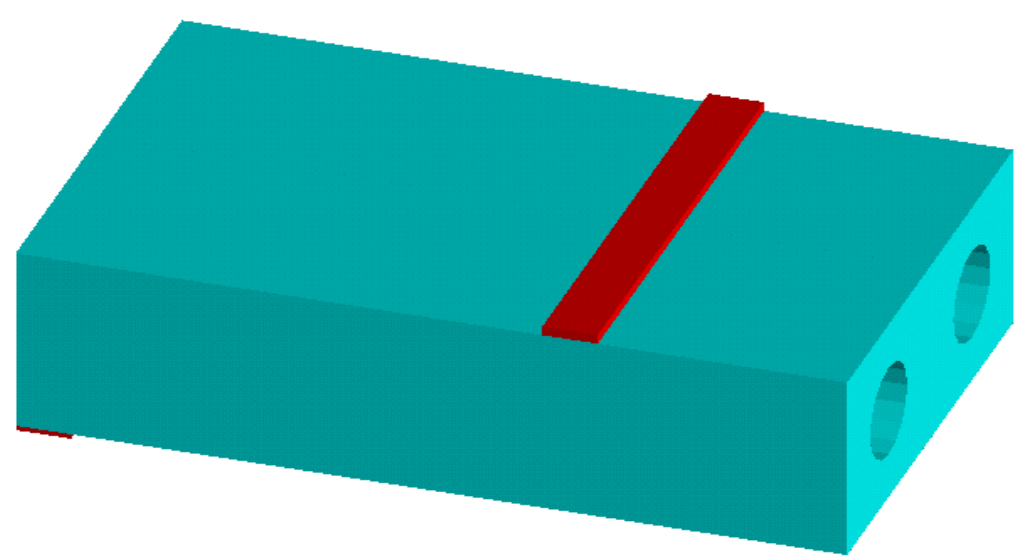

Fig. 3: A-A section

\section{Recognition of Behaviour Validity of the Proposed Model}

In this section, we compare the results obtained from analysis of finite element and the laboratory results. The comparisons include: load-displacement diagram, study of crack distribution during the loading and study of stress rate in the voided slab.

\section{Load-Displacement Diagram in the Source Model}

In order to make sure about the model built in ANSYS software, the results have been compared to results from the laboratory research by Yanesari and Ali Modanlou [3]. 
Figure 4 shows that load-displacement diagram of the limit element method has a high correspondence to the laboratory results. Also, table 3 shows the comparison of the results from the control slab.

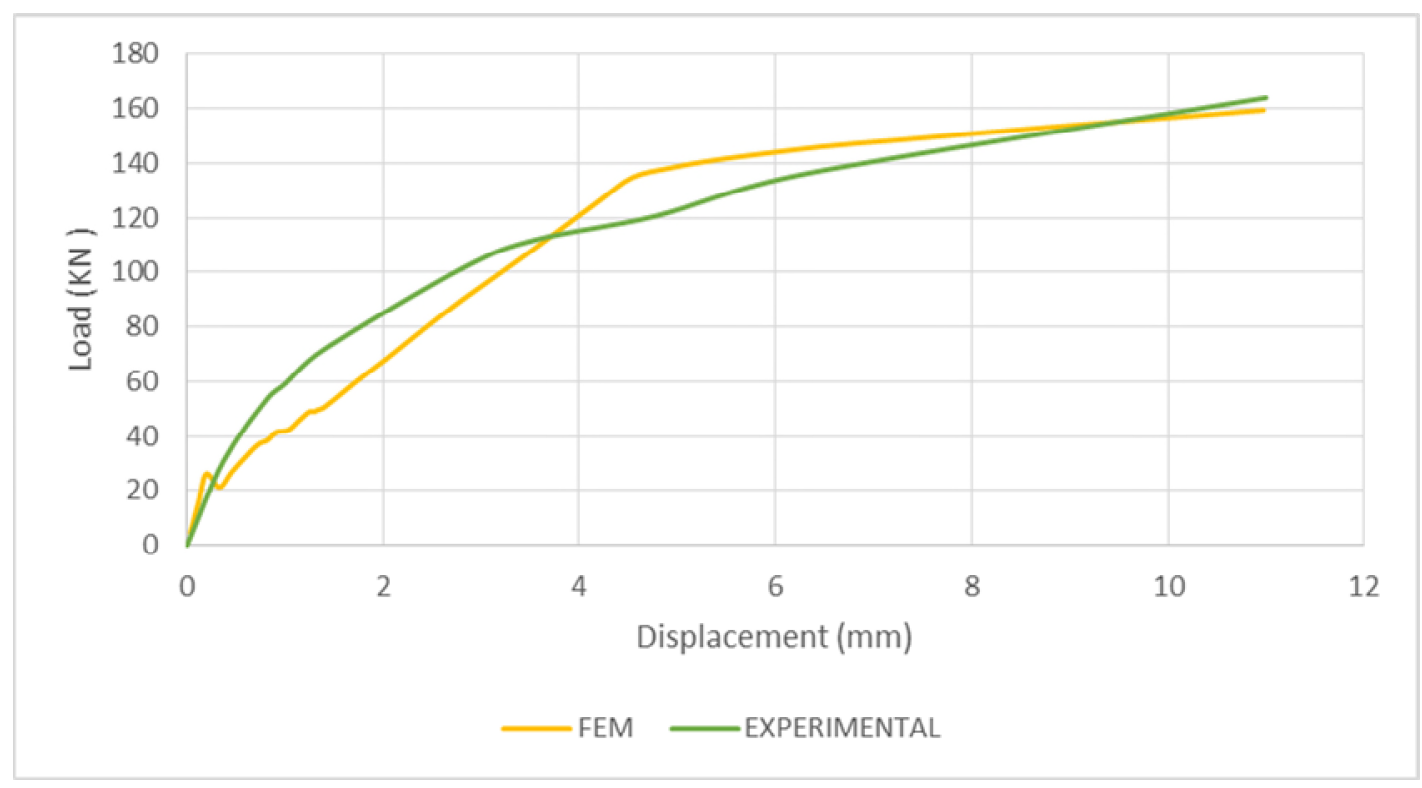

Fig. 4: Load - Displacement diagram.

The load difference rate in extreme of the concrete slab can be observed in table 3 :

Table 3: Comparison of the Results from Control Slab

\begin{tabular}{|c|c|}
\hline Ultimate load $(\mathrm{KN})$ & Control slab \\
\hline 165 & Laboratory sample \\
\hline 160 & Numerical analysis \\
\hline $3 \%$ & Error percentage \\
\hline
\end{tabular}

\section{Study of Crack Distribution during the Loading}

Figure 5 shows the cracked model of the laboratory sample and figure 6 shows evolution of crack pattern in the voided slab in different steps of loading.

As it is observed in the figures, in the control slab crack pattern, the cracks have been of flexural (90 degrees) type. Also, these cracks have been increased due to load increase and the slab has been ruptured due to flexural cracks. Considering the laboratory model of Yanesari and Ali Modanlou [3] shown in figure 5, a good correspondence is observed among the limit element cracked model and the laboratory model. 


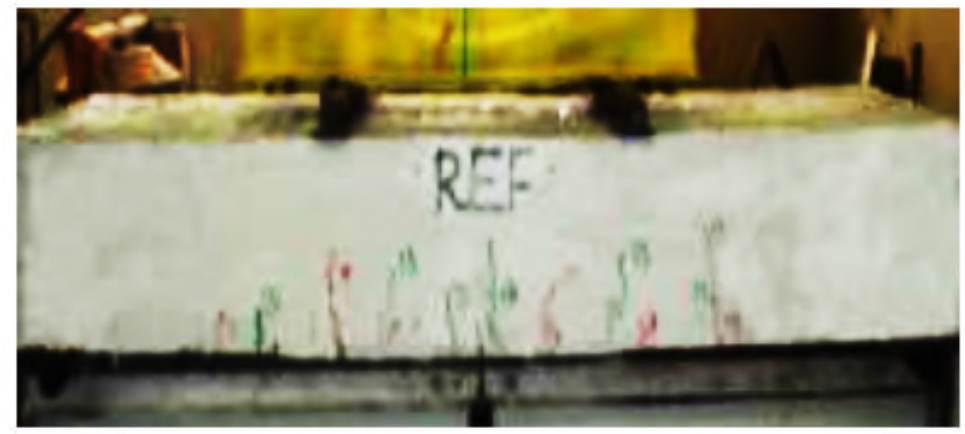

Fig. 5: Cracked model of the laboratory
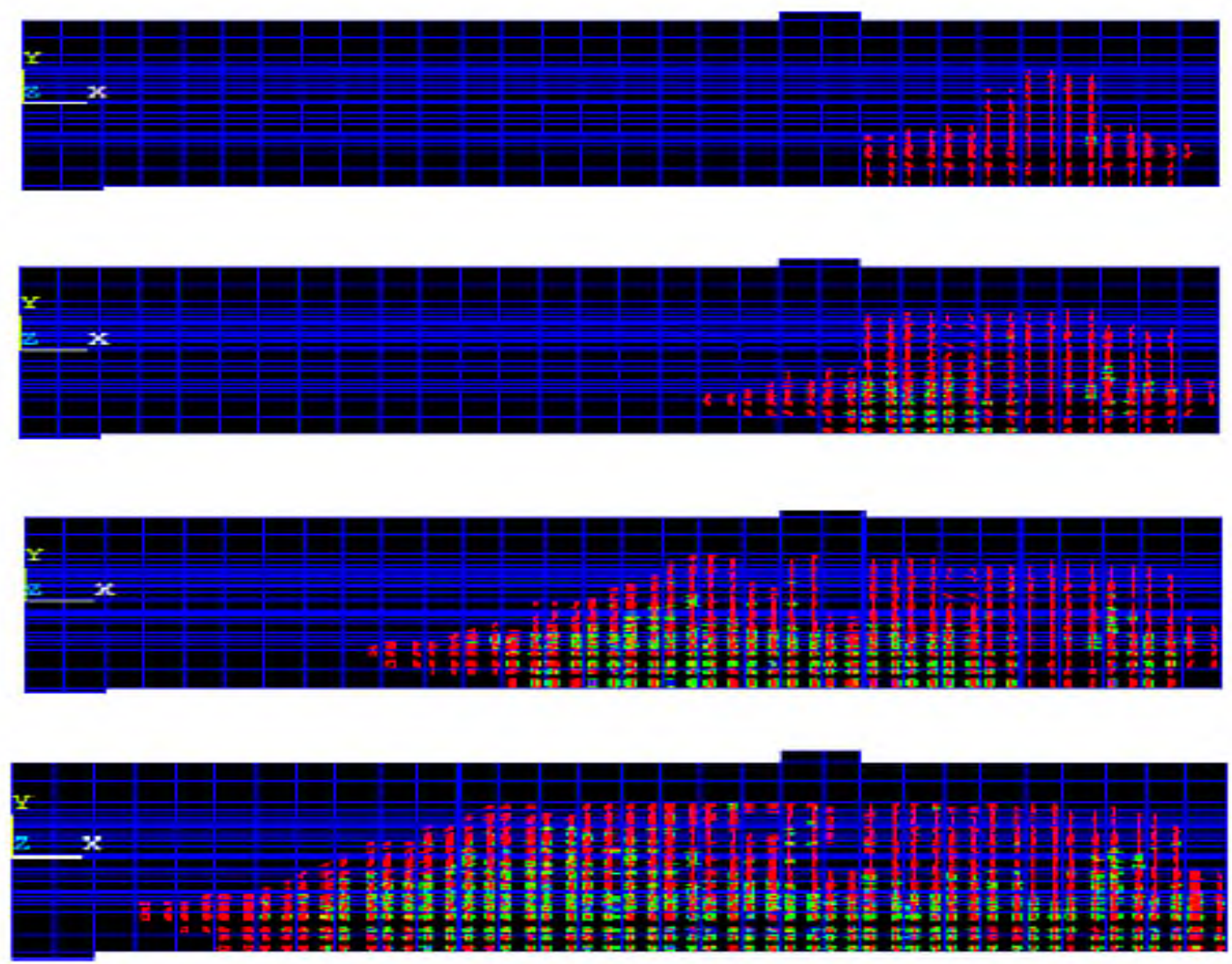

Fig. 6: Evolution of crack pattern in the control slab

\section{Study of Stress Rates in the Slap}

Considering figure 7 which shows Von Mises stress, it is observed that in final steps of loading the slap, in the compressive part, stress has reached its ultimate rate of compressive strength and also, it is observed in figure 8 that stress rates in tensional rebars (6 number 11 rebars placed in the lower part) have reached their flow rate in final step of loading. 

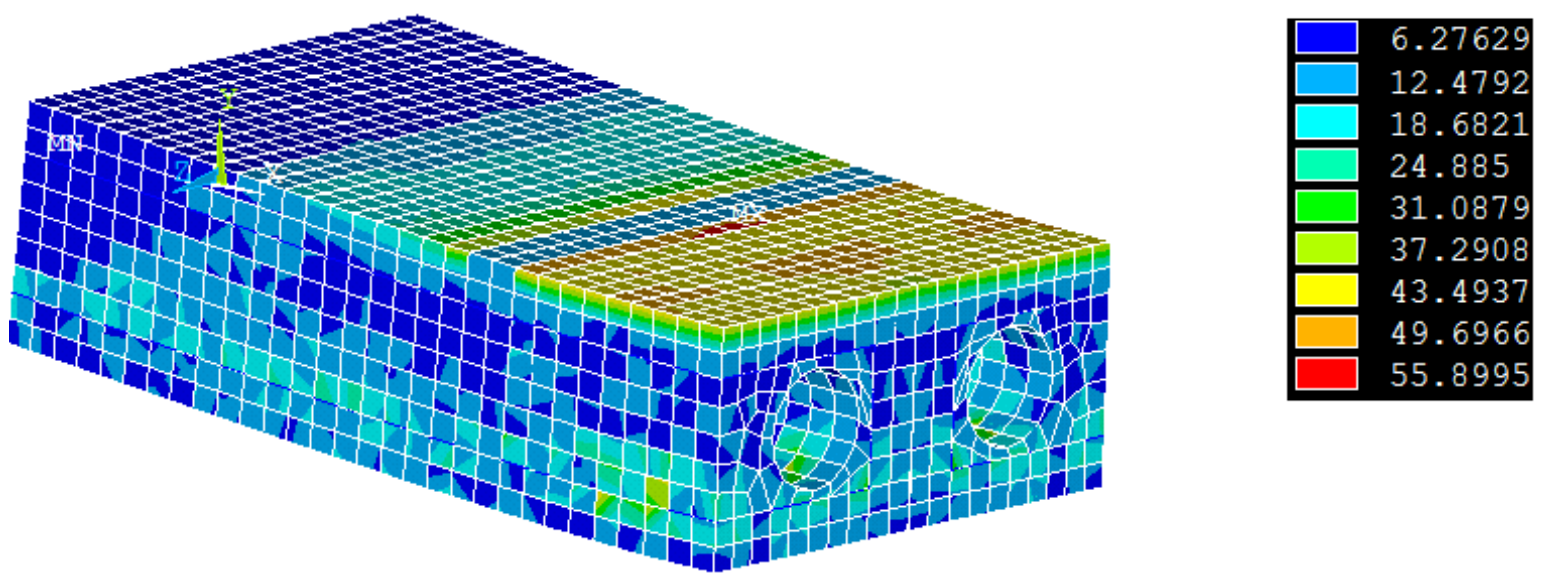

Fig. 7: Von Mises stress in concrete voided slab.

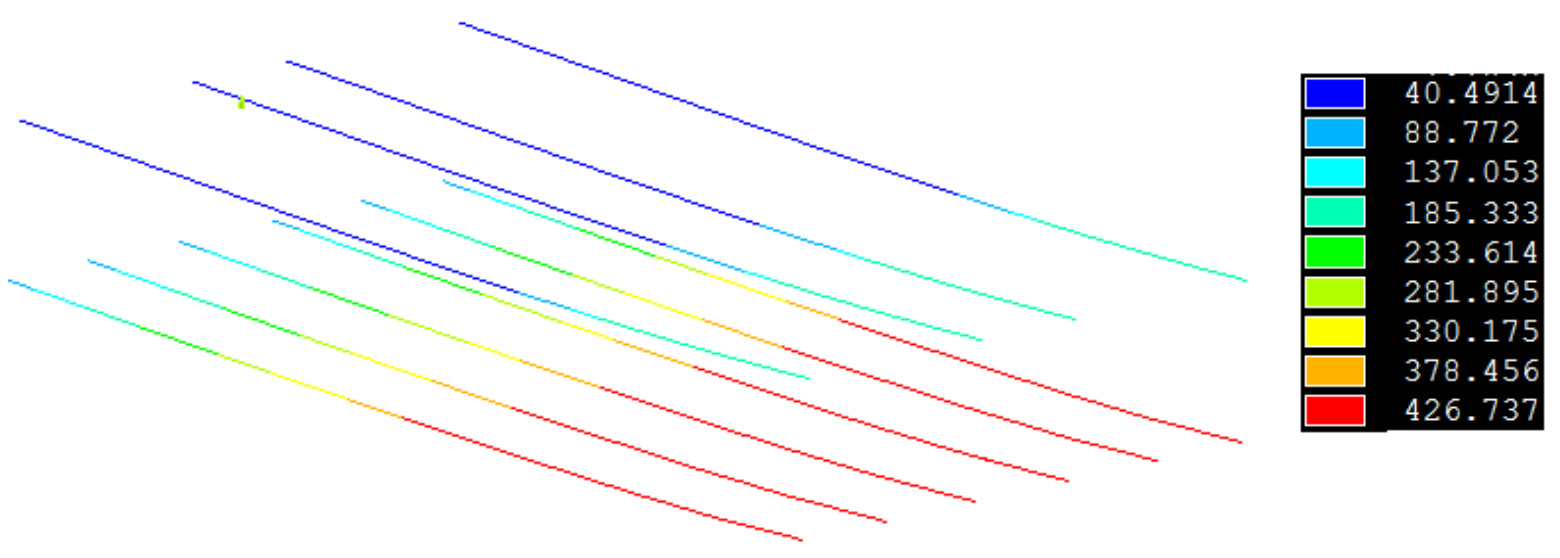

Fig. 8: Stress flow in slab tensional rebars.

\section{Parametric Study of Strengthening Concrete Slab Using FRP}

After validation of the source voided slab shown in previous section, the following has discussed the numerical studies of calculating flexural capacity of strengthened concrete voided slab by adding CFRP and GFRP fibers, also using maximum capacity of the composites in strengthening the concrete voided slab. After studying the flexural capacity of the slab strengthened with CFRP and GFRP fibers, changes in parameters of type and number of composite layers ( 2 and 3 layers) in the concrete voided slab are discussed. Then type of rupture and rates of stress in each model are discussed in order to study the type of damage including ductility or brittleness of the sample. Finally, having the type of rupture in the models, strengthening the voided slabs (with holes) using CFRP and GFRP fibers and impacts of each of these fibers in capacity of the slab are discussed.

\section{Impact of Type and Material of the Composite in Control Voided Slab}

To study the impact of type and material of the composite in order to strengthen the slab in terms of capacity on behaviour and strength of the structure, the mentioned slab which has the properties of the control slab $(\mathrm{m}=1.5 \mathrm{~m})$ is strengthened with different composites (CFRP and GFRP) and then analyzed and CFRP and GFRP layers are separately added to the slab in 
order to study how to change flexural capacity, potential rupture mode and type of crack in the slap. Figure 9 shows a voided slab sample with fibers.

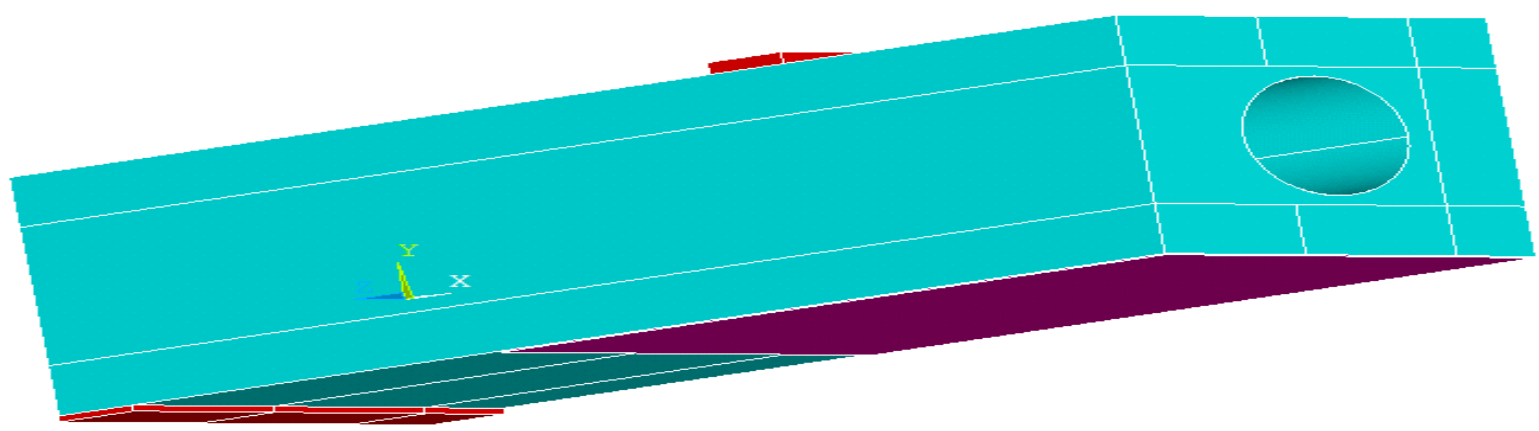

Fig. 9: One fourth of voided slab considering FRP layer.

\section{Study of Control Voided Slab Capacity by Adding Fibers $(\mathrm{L}=1.5 \mathrm{~m})$}

By adding FRP fibers in control slab, as it is observed in load-displacement diagram in figure 10 , by increase in the elasticity module in the voided slab, ultimate load-bearing of the structure is increased but behaviour of the structure becomes more brittle. Also, change rate of the stress in carbon composite (CFRP) to the plastic level is more compared to glass composites (GFRP).

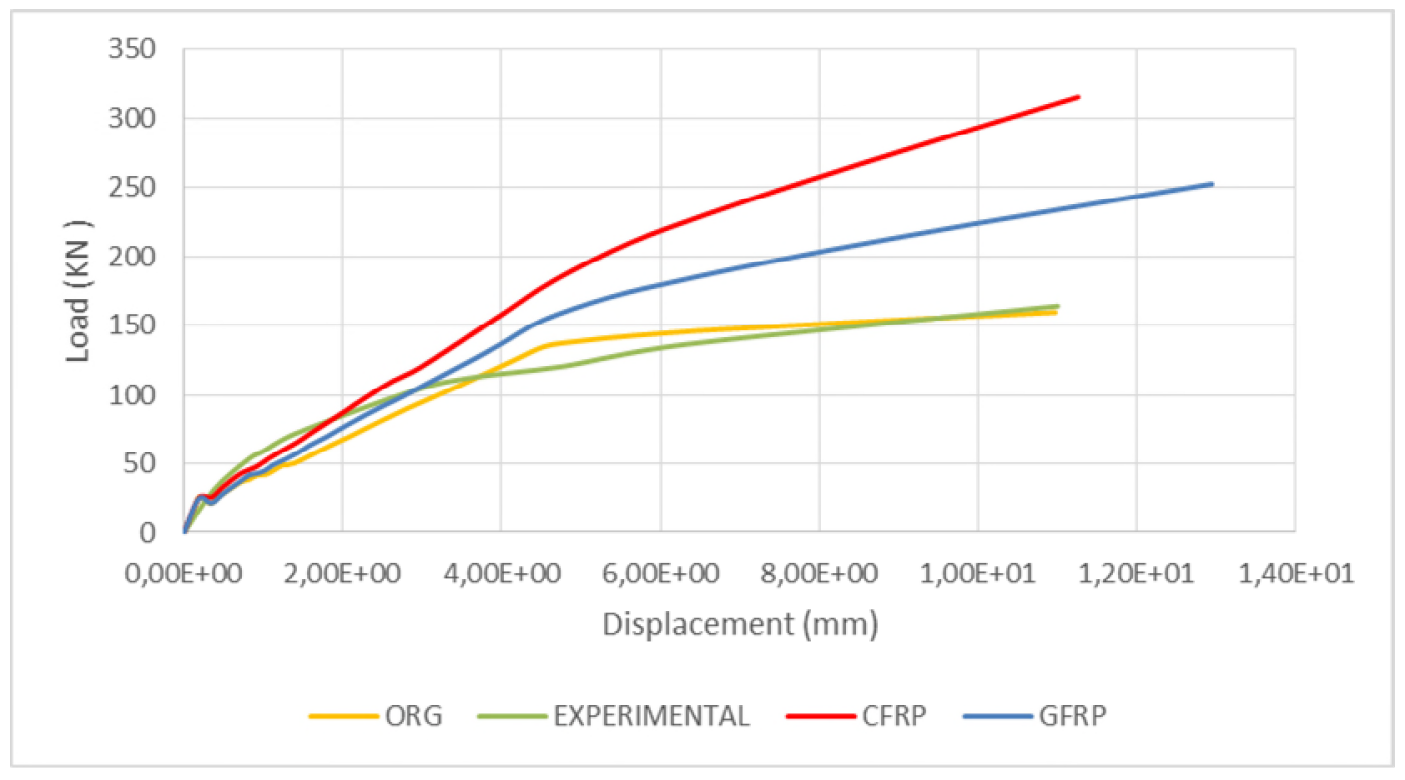

Fig. 10: Load - Displacement diagram with adding fibers (CRRP - GFRP).

Considering the rates of loading capacity difference and type of rupture in the voided slab, a summary of loading capacity difference percentage is observed in table 4 . 
Bulletin de la Société Royale des Sciences de Liège, Vol. 85, 2016, p. 1740 - 1755

Table 4: Differences of Ultimate Load Rate and Type of Rupture

\begin{tabular}{|c|c|c|c|}
\hline $\begin{array}{c}\text { Increase of Ultimate Load } \\
\text { after Strengthening }(\%)\end{array}$ & $\begin{array}{c}\text { Ultimate } \\
\text { Load }(\mathrm{KN})\end{array}$ & $\begin{array}{c}\text { Type of } \\
\text { Rupture }\end{array}$ & Voided slab \\
\hline- & 160 & $\begin{array}{c}\text { Flexural } \\
\text { rupture }\end{array}$ & $\begin{array}{c}\text { Model with a length of } \\
1 / 5 \text { metres (ORG) }\end{array}$ \\
\hline 97 & 315 & $\begin{array}{c}\text { Flexural } \\
\text { rupture }\end{array}$ & CFRP model \\
\hline 58 & 252 & $\begin{array}{c}\text { Flexural } \\
\text { rupture }\end{array}$ & GFRP model \\
\hline
\end{tabular}

\section{Study of the Ultimate Loading Capacity of the Voided Slab by Changing Type and Number of Composite layers in Control Model}

To study the impact of layer number or thickness of FRP plates in strengthening the voided slabs, models strengthened with 2 and 3 layers of CFRP and GFRP fibers with a condition similar to the control model, with a size of $150 \times 45 \times 20 \mathrm{~cm}$ and 2 holes with a diameter of 10 $\mathrm{cm}$ were made in the middle and along the slab's length in which 1 layer of FRP has been used for strengthening and then, in terms of the manner of changes in flexural capacity, the probable rupture mode and type of rupture have been compared in the voided slab.

By increase in number of composite laminate layers in the strengthened voided slab, as shown in the load-displacement diagram of figures 11 and 12, it is observed that this has caused increase in capacity of the voided slab.

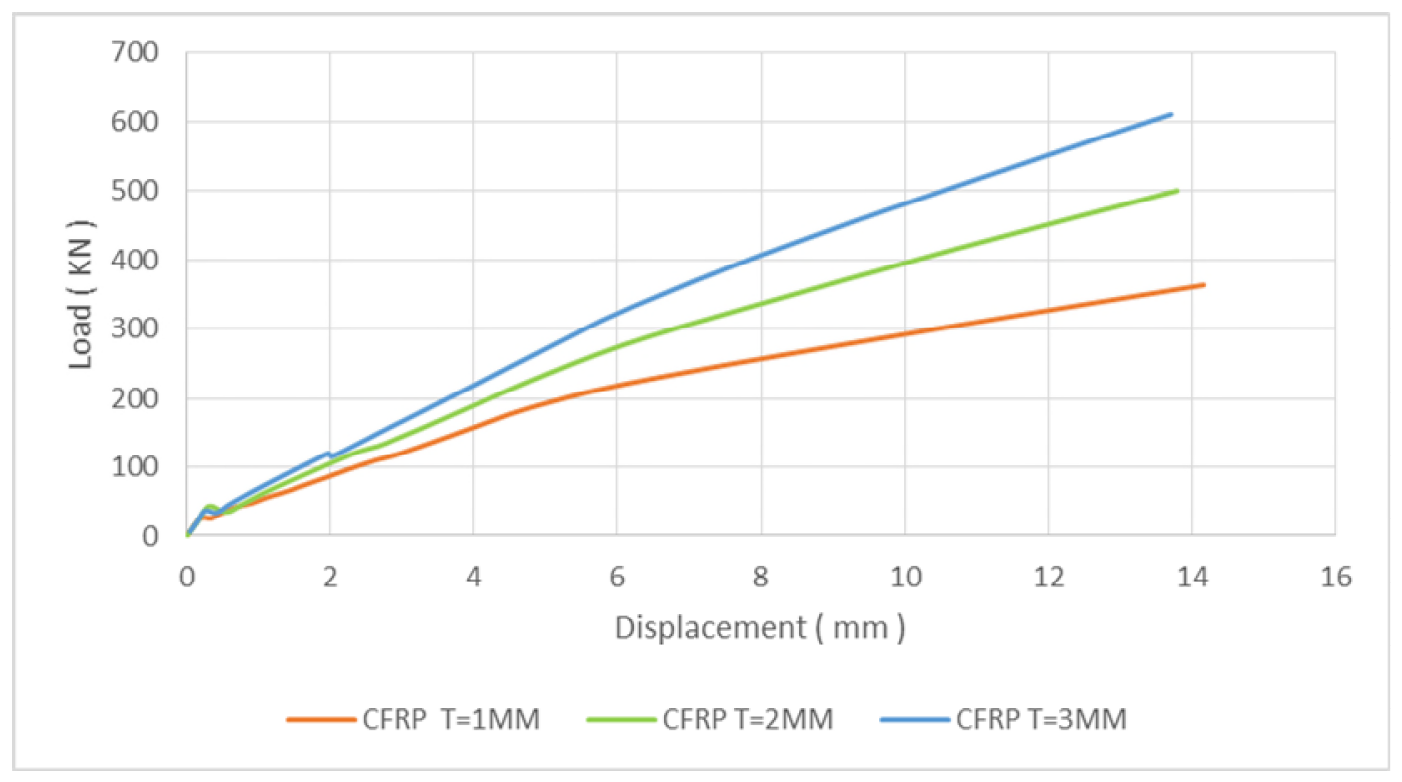

Fig. 11: Load - Displacement diagram for CFRP fiber in control model ( $\mathrm{L}=1 / 5 \mathrm{~m})$. 
Bulletin de la Société Royale des Sciences de Liège, Vol. 85, 2016, p. 1740 - 1755

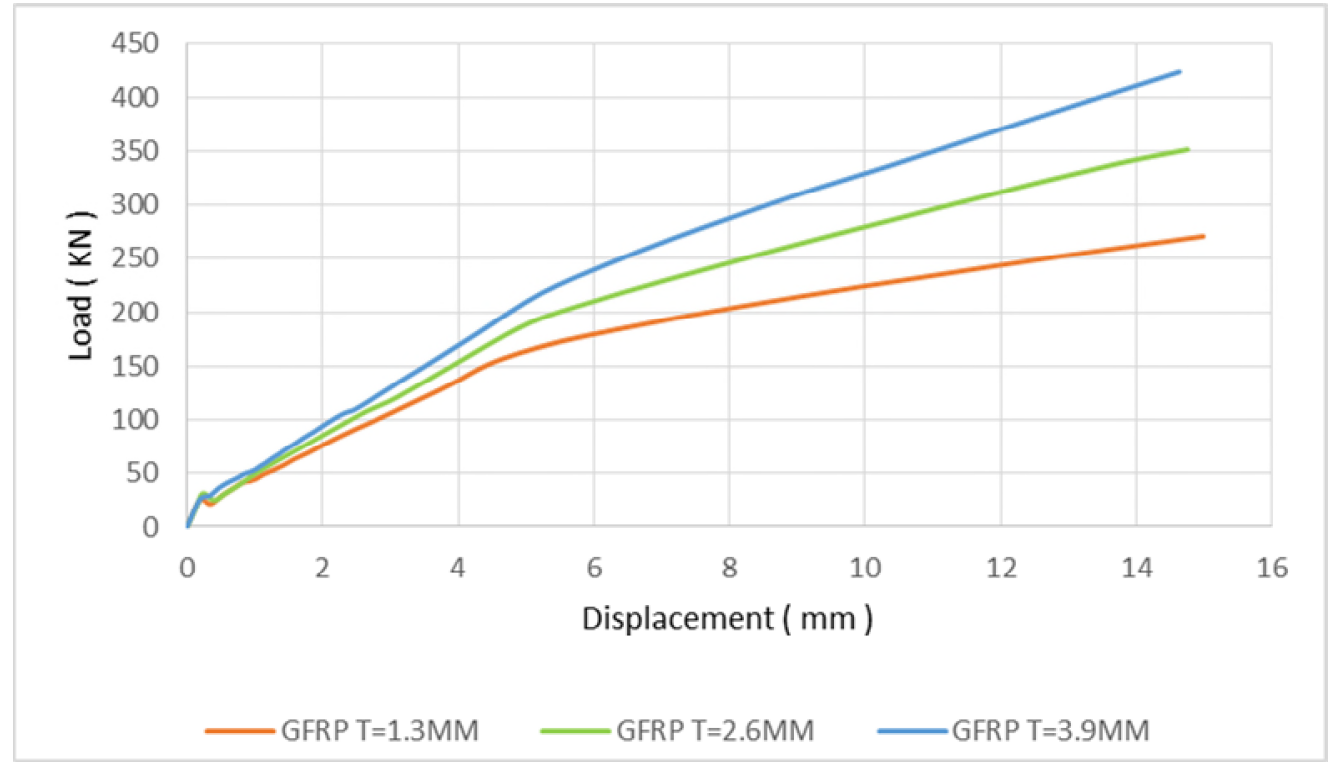

Fig. 12: Load - Displacement diagram for GFRP fiber in control model $(\mathrm{L}=1 / 5 \mathrm{~m})$.

\section{Study of Crack Distribution during the Loading in the Control Model $(\mathrm{L}=1.5 \mathrm{~m})$}

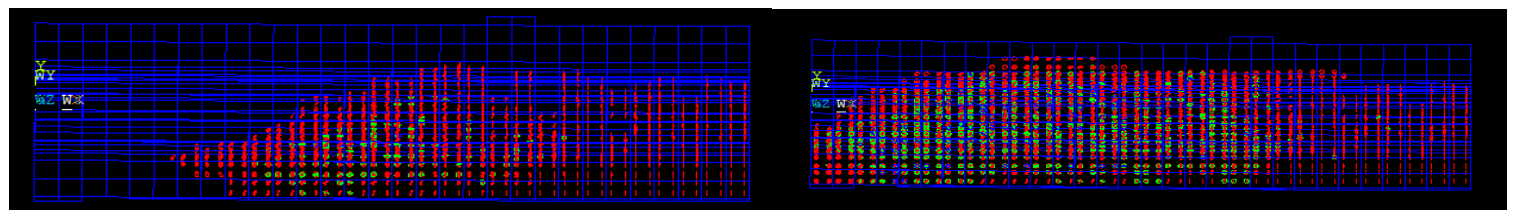

Fig. 13: Crack Distribution in control model voided slab with 2 CFRP layer ( $L=1 / 5 \mathrm{~m}$ ).

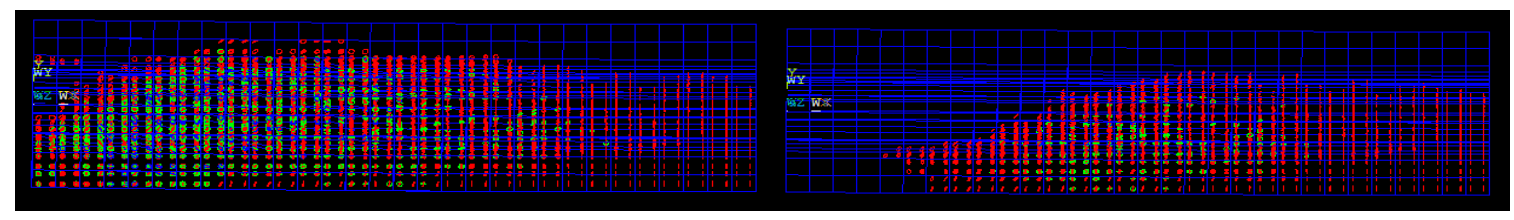

Fig. 14: Crack Distribution in control model voided slab with 3 CFRP layer ( $L=1 / 5 \mathrm{~m})$.

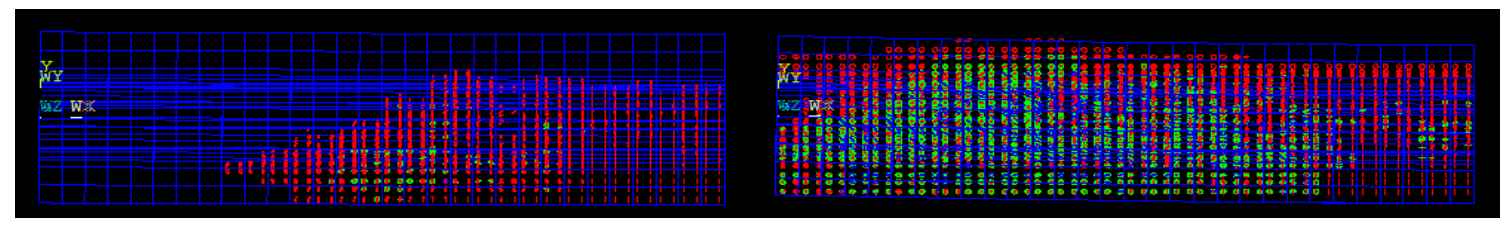

Fig. 15: Crack Distribution in control model voided slab with 2 GFRP layer ( $L=1 / 5 \mathrm{~m})$. 


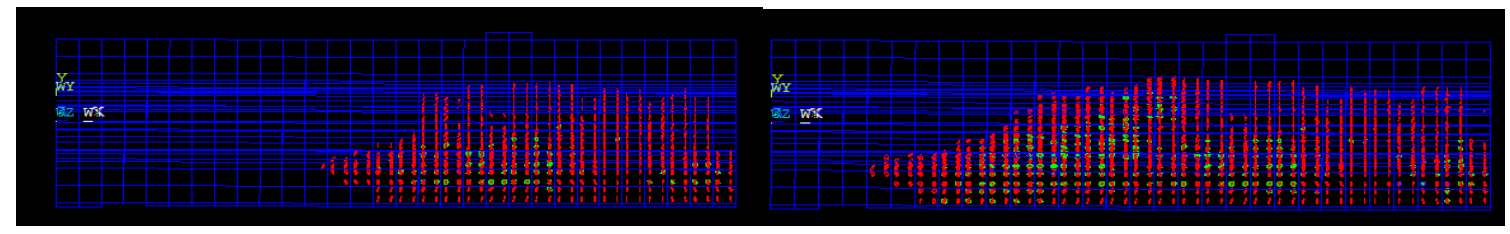

Fig. 16: Crack Distribution in control model voided slab with 3 GFRP layer ( $L=1 / 5 \mathrm{~m})$.

In order to study the rupture mode, considering the type of crack distribution in figures 13, 14,15 and 16 it is observed that the flexural rupture mode has happened to these slabs.

Considering the loading capacity difference rates and type of rupture in voided slab, table 5 shows a summary of loading capacity difference percentage is observed.

Table 5: The Difference of Ultimate Load Rates and Type of Rupture in the Control Model (L=1.5m)

\begin{tabular}{|c|c|c|c|}
\hline $\begin{array}{c}\text { Increase in ultimate } \\
\text { load after } \\
\text { strengthening }\end{array}$ & $\begin{array}{c}\text { Ultimate } \\
\text { load }\end{array}$ & Type of rupture & $\begin{array}{c}\text { Type and thickness of the fiber used } \\
\text { in strengthening the voided slab }\end{array}$ \\
\hline- & 363 & $\begin{array}{c}\text { Flexural } \\
\text { strengthening }\end{array}$ & $\begin{array}{c}\text { CFRP model with a thickness of } 1 \\
\text { mm }\end{array}$ \\
\hline 68 & 500 & $\begin{array}{c}\text { Flexural } \\
\text { strengthening }\end{array}$ & $\begin{array}{c}\text { FFRP model with a thickness of } 2 \\
\text { mm }\end{array}$ \\
\hline 38 & 271 & $\begin{array}{c}\text { Flexural } \\
\text { strengthening }\end{array}$ & $\begin{array}{c}\text { GFRP model with a thickness of 3 } \\
\text { mm }\end{array}$ \\
\hline 56 & 423 & $\begin{array}{c}\text { Flexural } \\
\text { strengthening } \\
\text { mm }\end{array}$ & $\begin{array}{c}\text { GFRP model with a thickness of } 2.6 \\
\text { mm }\end{array}$ \\
\hline 30 & 351 & $\begin{array}{c}\text { Flexural } \\
\text { strengthening }\end{array}$ & $\begin{array}{c}\text { GFRP model with a thickness of 3.9 } \\
\text { mm }\end{array}$ \\
\hline
\end{tabular}

\section{Study of Stress Rate in the Voided Slab by Changing Type and Number of FRP Layers in the Control Model $(\mathrm{L}=1.5 \mathrm{~m})$}

In order to determine flexural capacity of a concrete voided slab by applying displacement push, the Von mises stress are observed in 17, 18, 19, 20 figures that in final steps of loading, stress in compression part has reached its ultimate rate and also, stress values in stress rebars in the final step of loading has reached its flow values. 


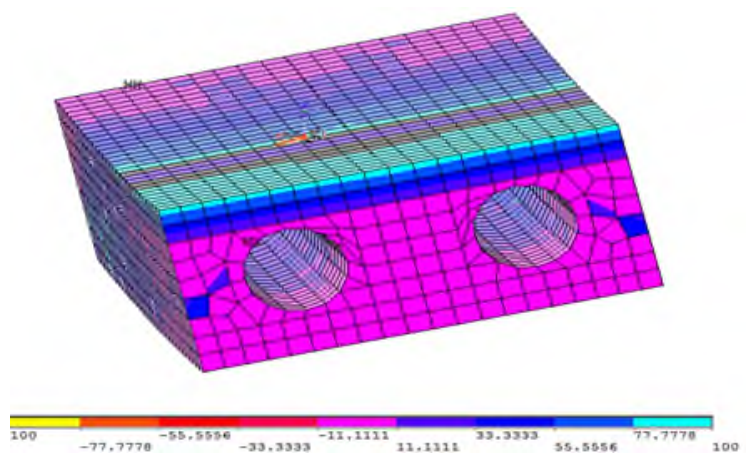

Fig. 17: Stress in 2 CFRP layer voided slab.
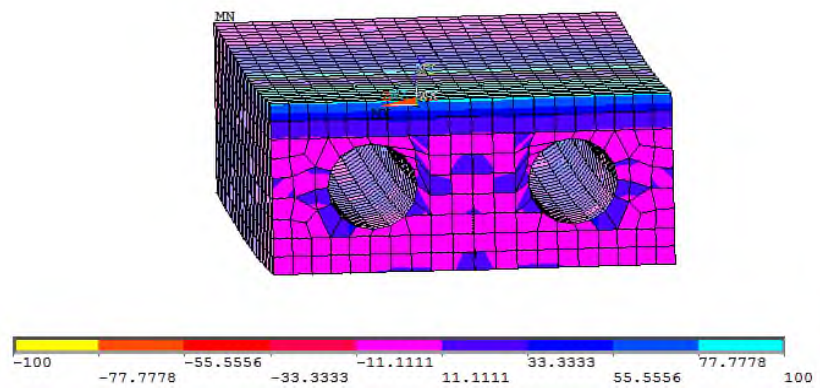

Fig. 19: Stress in 2 GFRP layer voided slab.

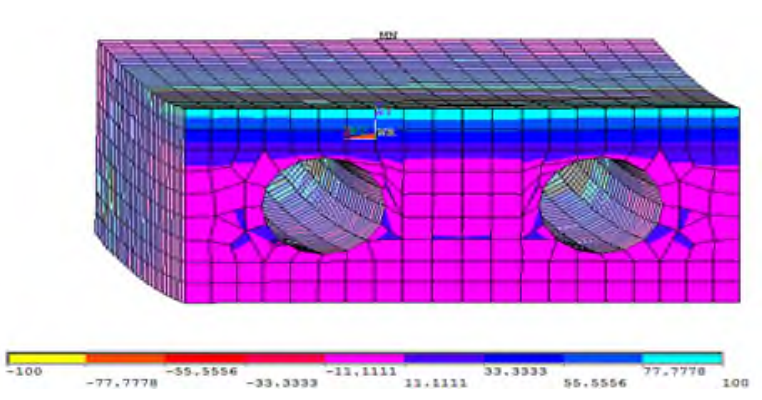

Fig. 18: Stress in 3 CFRP layer voided slab.
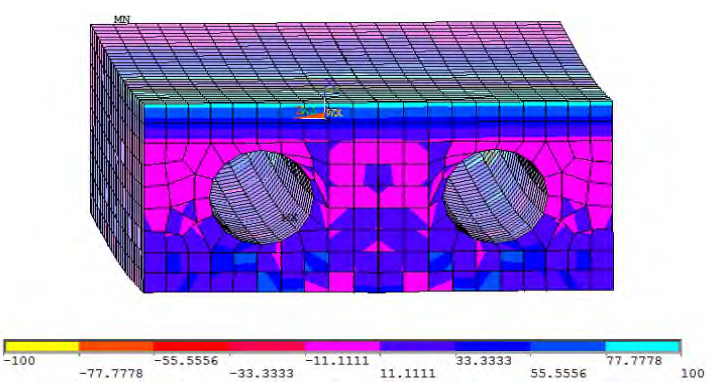

Fig. 20: Stress in 3 GFRP layer voided slab.

\section{Study of Ultimate Loading Capacity of Voided Slab by Changing the Type and Number of Composite Layers in a Slab with a Length of 9 m}

In order to study the impact of layer number or thickness of FRP plates in strengthening the voided slabs, strengthened models with 2 and 3 layers of CFRP and GFRP fibers with conditions similar to the control model, with a size of $900 \times 45 \times 20 \mathrm{~cm}$ and 2 holes with a diameter of $10 \mathrm{~cm}$ were made in the middle and along the length of the slab in which 1 FRP layer has been used for strengthening and then, in terms of the manner of changes in flexural capacity, potential rupture mode and type of crack have been compared in the voided slab.

By increase in the number of composite laminate layers in strengthened voided slab, as shown in load-displacement diagram of figures 21 and 22, it is observed that this has lead to an increase in capacity of voided slab. 
Bulletin de la Société Royale des Sciences de Liège, Vol. 85, 2016, p. 1740 - 1755

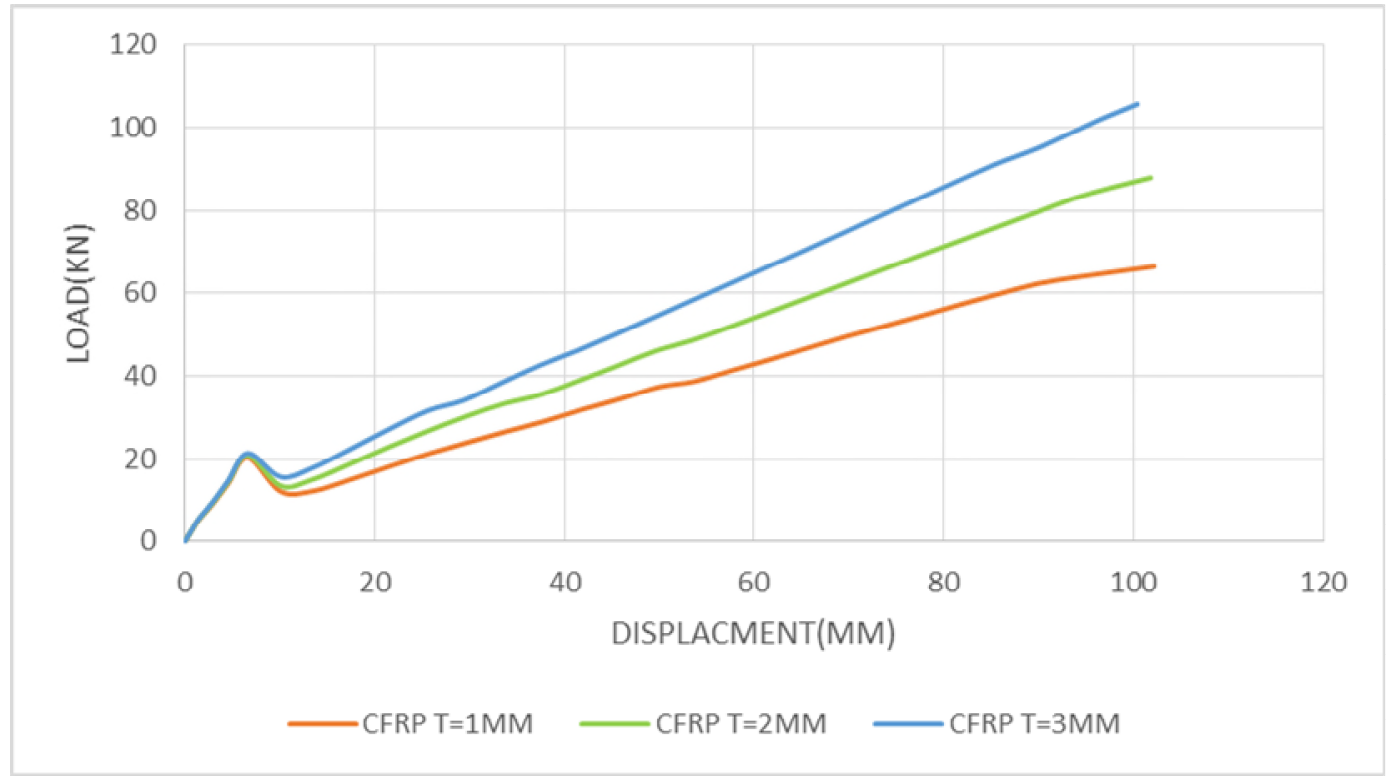

Fig. 21: Model of Load - Displacement diagram for CFRP fiber ( $\mathrm{L}=9 \mathrm{~m})$.

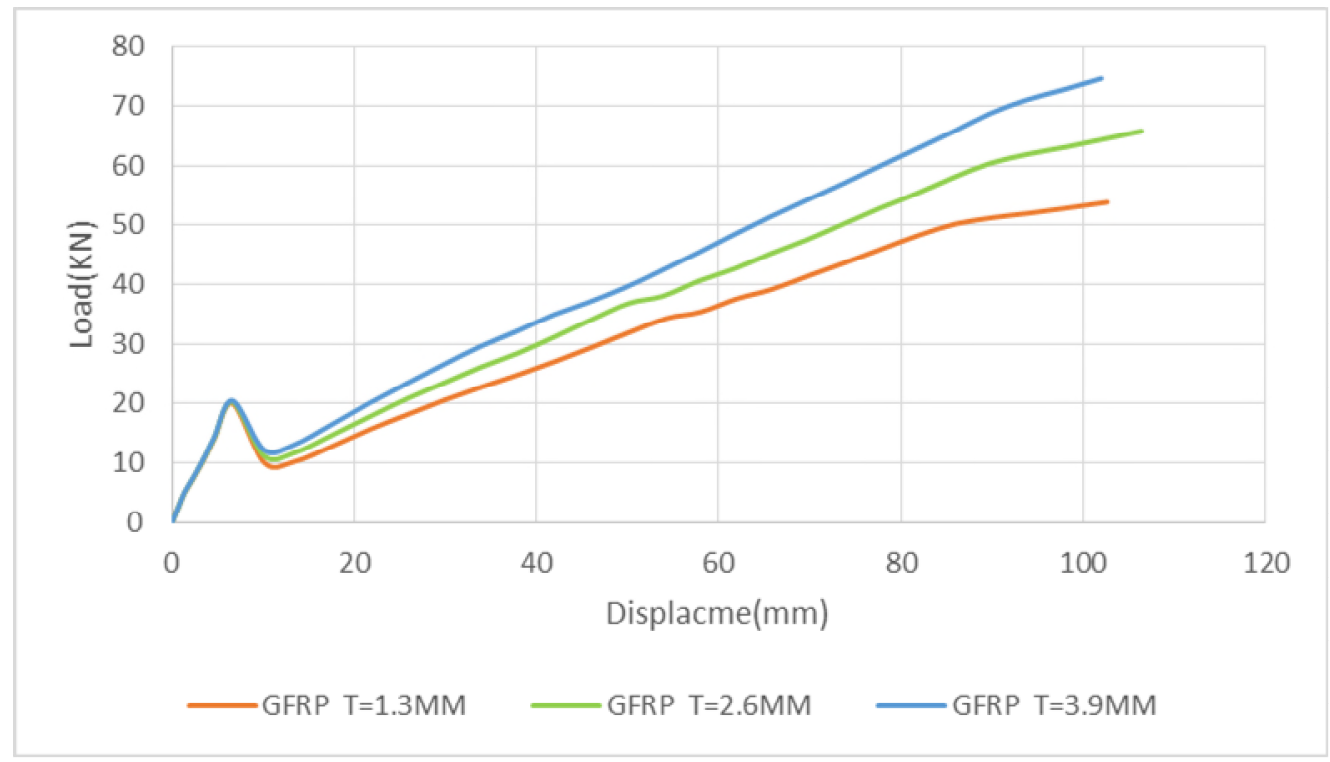

Fig. 22: Model of Load - Displacement diagram for GFRP fiber ( $\mathrm{L}=9 \mathrm{~m})$.

16. Study of Crack Distribution during the Loading in a Voided Slab Model with a Length of 9 Metres
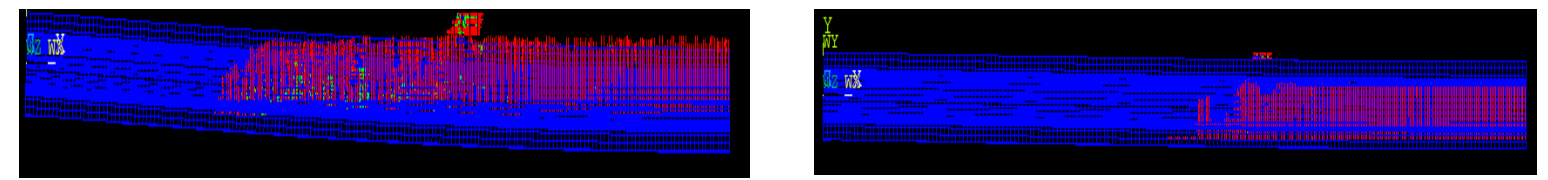

Fig. 23: Crack Distribution of 2 CFRP layer voided slab in 9 meter length model. 
Bulletin de la Société Royale des Sciences de Liège, Vol. 85, 2016, p. 1740 - 1755
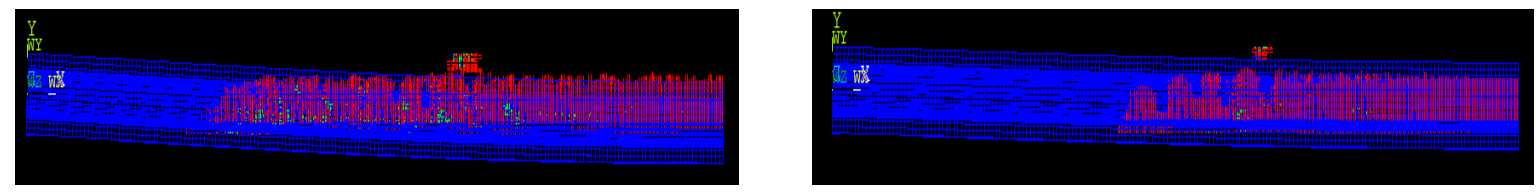

Fig. 24: Crack Distribution of 3 CFRP layer voided slab in 9 meter length model.
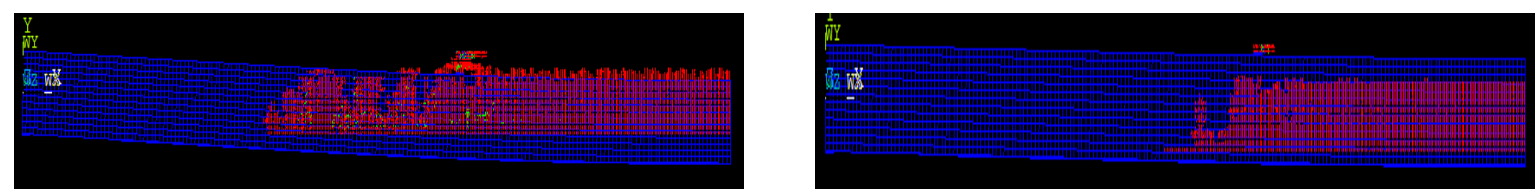

Fig. 25: Crack Distribution of 2 GFRP layer voided slab in 9 meter length model.
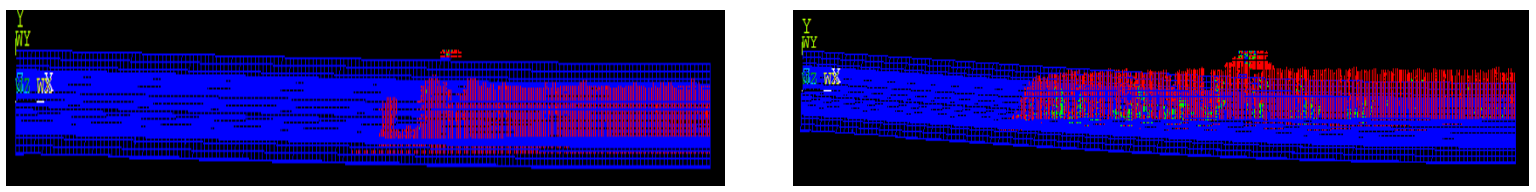

Fig. 26: Crack Distribution of 3 GFRP layer voided slab in 9 meter length model.

To study the rupture mode, considering the type of crack distribution in figures 23, 24, 25 and 26 it is observed that flexural rupture mode has happened for these slabs.

Considering the values of loading capacity difference and type of rupture in voided slab, table 6 shows a summary of loading capacity difference percentage.

Table 6 : Differences of Ultimate Load Values and Rupture Type in a Slap with a Length of $9 \mathrm{~m}$.

\begin{tabular}{|c|c|c|c|}
\hline $\begin{array}{c}\text { Increase in ultimate } \\
\text { load after } \\
\text { strengthening }\end{array}$ & $\begin{array}{l}\text { Ultimate load } \\
\qquad(\mathrm{KN})\end{array}$ & $\begin{array}{l}\text { Type of } \\
\text { fracture }\end{array}$ & $\begin{array}{l}\text { Type and thickness of the fibers } \\
\text { used in strengthening voided slab }\end{array}$ \\
\hline- & 66 & $\begin{array}{l}\text { Flexural } \\
\text { rupture }\end{array}$ & $\begin{array}{l}\text { CFRP model with a thickness of } 1.3 \\
\mathrm{~mm}\end{array}$ \\
\hline 59 & 105 & $\begin{array}{l}\text { Flexural } \\
\text { rupture }\end{array}$ & $\begin{array}{c}\text { CFRP model with a thickness of } 2.6 \\
\mathrm{~mm}\end{array}$ \\
\hline 32 & 87 & $\begin{array}{l}\text { Flexural } \\
\text { rupture }\end{array}$ & $\begin{array}{c}\text { CFRP model with a thickness of } 3.9 \\
\mathrm{~mm}\end{array}$ \\
\hline- & 53 & $\begin{array}{l}\text { Flexural } \\
\text { rupture }\end{array}$ & $\begin{array}{l}\text { GFRP model with a thickness of } \\
1.3 \mathrm{~mm}\end{array}$ \\
\hline 40 & 74 & $\begin{array}{l}\text { Flexural } \\
\text { rupture }\end{array}$ & $\begin{array}{l}\text { GFRP model with a thickness of } \\
2.6 \mathrm{~mm}\end{array}$ \\
\hline 21 & 64 & $\begin{array}{l}\text { Flexural } \\
\text { rupture }\end{array}$ & $\begin{array}{l}\text { GFRP model with a thickness of } \\
3.9 \mathrm{~mm}\end{array}$ \\
\hline
\end{tabular}




\section{Study of Stress Rates in Voided Slab by Changing the Type and Number of FRP Layers in the Voided Slab Model with a Length of 9 m}

In order to determine flexural capacity of concrete voided slab by applying displacement push, Von mises stress values in figures 27, 28, 29 and 30, it is observed that in final steps of loading, stress in compression section reaches its ultimate value and also, stress values in stress rebars in final loading step reach their flow values.

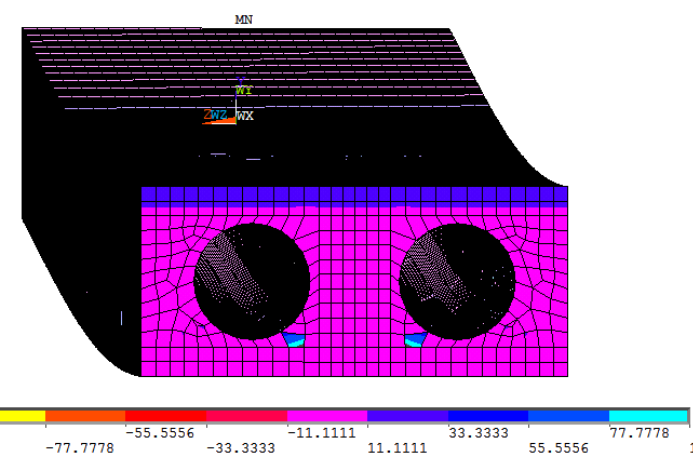

Fig. 27: Stress in 2 CFRP layer voided slab.

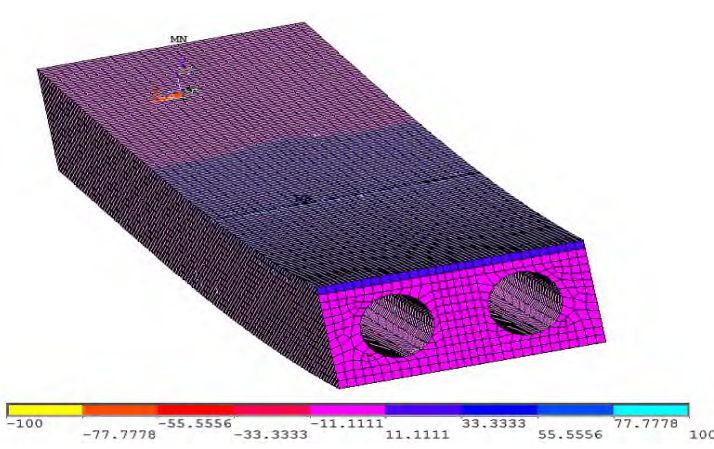

Fig. 29: Stress in 2 GFRP layer voided slab.

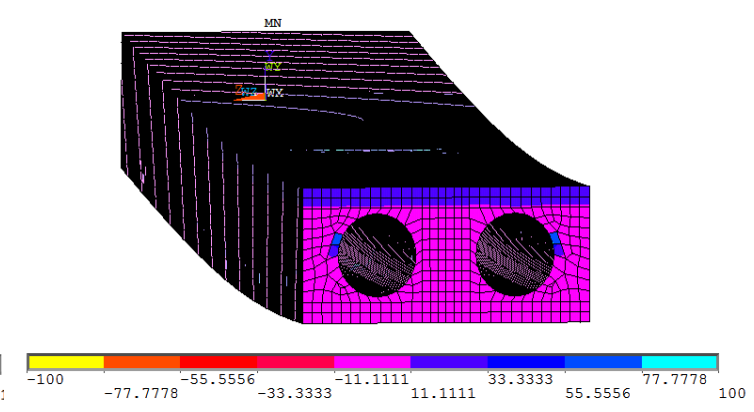

Fig. 28: Stress in 3 CFRP layer voided slab.
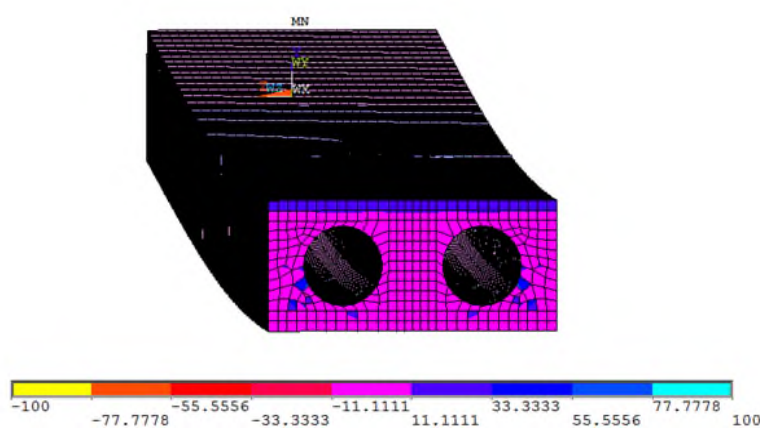

Fig. 30: Stress in 3 GFRP layer voided slab.

\section{Conclusions}

The new FRP technology has a specific place in field of strengthening the structures. Due to having distinctive features such as a high strength-to-weight ratio, durability against corrosion etc., today various structures are strengthened using this technology all around the world. Present article has discussed the impact of type and number of FRP layers in strengthening the concrete voided slabs. For this purpose a voided slab has been selected as the control (source) slab. Then, the mentioned slab has been modelled in ANSYS software and after validation of the sample, rest of the research has discussed the impacts of change in parameters of type and number of composite layers (thickness of fibers) in strengthening the voided slab in two states of using CFRP and GFRP laminates which lead to the following results: 
1. By increase in number of composite laminates or in other words, by increase in thickness of composite laminates, yield load and rupture load of the structure is significantly increased.

2. By increase in number of composite plates or thickness of FRP fibers, ductility of the structure is decreased and the structure becomes brittle.

3. The slabs strengthened with GFRP fibers show a higher ductility compared to the slabs strengthened with CFRP fibers in all states and thicknesses.

4. Ultimate strength of the slabs strengthened with GFRP fibers show a lower flexural capacity compared to the slabs strengthened with CFRP fibers in all states and thicknesses. Therefore, when increase in the final capacity is important, strengthening the slab with CFRP fibers is advised and if ductility of the structure is preferred, using the GFRP fibers is more appropriate.

\section{References}

[1] Taljsten, B., "Strengthening of Existing Concrete Structures with Epoxy Bonded Plates of Steel or Fiber Reinforcement Plastics", J Mater Civil Eng, 26(4), pp. 206-12, (1997).

[2] Ahmed Khalifa, William J.Gold, Antonio Nanni, Abdel Aziz M.I. "Contribution of Externally Bonded FRP to Shear Capacity of Flexural Members" ASCE-Journal of Composites for Construction, Vol 2, No 4, Nov1998 pp.195-203.

[3] Finite Element Analysis Using ANSIS, Shabanali, M. R., Nas Publications

[4] Flexural and Flexural-Shear Strengthening of Voided Slabs of Reinforced Concrete Using CFRP and GFRP Fibers and Steel Laminates, Ninth National Congress of Civil Engineering, Salehi Yanesari, M. M. \& Modanlou, A. April, 2012. 